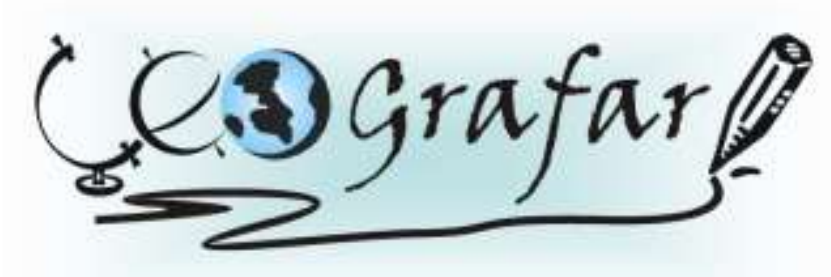

Revista Eletrônica do Programa de Pós-Graduaçāo em Geografla - UFPR

\title{
CULTURA E DEMARCAÇÃO DAS TERRAS DOS POVOS INDÍGENAS: DESAFIOS E OPORTUNIDADES NO BRASIL CONTEMPORÂNEO
}

\section{CULTURE AND DEMARCATION OF THE LANDS OF INDIGENOUS PEOPLES: CHALLENGES AND OPPORTUNITIES IN CONTEMPORARY BRAZIL}

\section{(Recebido em 20-06-2018; Aceito em: 28-09-2018)}

Irenildo Costa da Silva Doutorando no Programa de Pós-Graduação em Integração da América Latina da Universidade de São Paulo (USP) silvaic2009@hotmail.com

\section{Resumo}

Pretendemos neste artigo traçar argumentos e reflexões que perpassem como um fio condutor carregando debates que acreditamos "jogar" luz na articulação de densidades teórico-metodológicas e analíticas sobre questões indígenas no Brasil contemporâneo, considerando como mediação das nossas linhas de analises o estudo da cultura, que perpassa para além da materialidade, como uma chave para interpretar desafios e oportunidades vivenciados pelos povos indígenas no Brasil, seja nas questões políticas, sociais, culturais, e com maiores delineamento no que se refere à demarcação de terras desses povos. Nessa empreitada, optamos por utilizar as abordagens culturais no âmbito político e científico da Geografia, identificando no debate da pós-modernidade, não se referindo a uma ruptura com a modernidade, os elementos que atendem de maneira mais elucidatória os objetivos aqui pretendidos, que entrecruzam o debate da cultura no tocante às hibridizações culturais e um reencantamento do mundo para interpretar as coisas e os sujeitos.

Palavras-chave: Povos indígenas; Cultura; Demarcação de terras.

\section{Abstract}

We intend in this article to draw up arguments and reflections that permeate as a thread carrying debates that we believe play in the articulation of theoretical-methodological and analytical densities on indigenous issues in contemporary Brazil, considering as mediation of our lines of analysis the study of culture that goes beyond materiality as a key to interpreting the challenges and opportunities lived by indigenous peoples in Brazil, whether in political, social, cultural, and with greater delineation regarding the demarcation of lands of these peoples. In this endeavor, we chose to use cultural approaches in the political and scientific sphere of Geography, identifying in the postmodern debate, not referring to a rupture with modernity, the elements that serve in a more elucidatory way the 
objectives here, which intersect the cultural debate on cultural hybridizations and a re-enchantment of the world to interpret things and subjects.

Keywords: Indigenous people; Culture; Demarcation of lands.

\section{Introdução}

Debates sobre a questão indígena é um esforço bastante pertinente para a realidade atual seja no âmbito político, jurídico, cultural e acadêmico em geral, em que os povos indígenas estão cada vez mais "acuados" por ações e atividades do homem não_indígena, o qual tem se mostrado pouco preocupado com questões relacionadas a esses povos, resguardadas as exceções. No avanço da mentalidade capitalista pela exploração e acumulação de riquezas o homem não indígena trava intensos esforços por explorar os territórios dos povos indígenas, os quais resistem, evocando não só as suas potencialidades físicas, mas, sobretudo, suas representações simbólicas imateriais ou materiais, as quais têm "certa" consolidação e reconhecimento de instituições governamentais, por meio de leis, não governamentais (ONGs) e de boa parte da sociedade que convergem para defender e assegurar a permanência de reprodução do modo de vida das populações indígenas.

Essas populações têm como principais demandas, como fator importante para assegurar suas culturas e tradições, a demarcação e reconhecimento de seus territórios e um Estado, o qual em muitas ocasiões é responsável por incentivar ou promover ações contrárias às pautas dos povos indígenas, que lhes garantam aparato jurídico e social diante daqueles que estão à porta ou já adentraram seus territórios apenas para explorar os recursos naturais, destruindo o meio e muitas das tradições dessas populações. As lutas dos povos indígenas saíram da invisibilidade, em que estiveram por muito tempo, para entrar de vez, como pauta específica, nas discussões do Brasil contemporâneo, em que ocorre ao longo de décadas debates calorosos sobre o processo da demarcação de terras indígenas.

É indiscutível a existência de proximidades e relações entre as populações indígenas e as não indígenas, mas até onde vai o limite dessas relações sem o comprometimento do modo de vida tradicional dessas populações, sendo aceitável por essas populações dentro das fronteiras que marcam o seu sistema social (BARTH, 1969; POUTIGNAT e STREIFF-FENART, 1998)? e, olhando pela lente daqueles que não são indígenas, até onde consideram aceitável reconhecer os direitos dessas populações?. Se por um lado se tem as instituições públicas, que, ressalvadas as exceções, agem em prol das populações indígenas por obrigatoriedade da lei, Ihes assegurando muitos dos direitos reconhecidos e consolidados nos arcabouços jurídicos; por outro, se tem a própria demanda feita pelos povos indígenas, os quais reconhecem nas instituições públicas, embora a existência de conflitos em muitas ações, o poder para Ihes proporcionar a reprodução dos seus modos de vida. 
Ainda, é fundamental ressaltar que para além dessas duas situações é de suma importância 0 papel de ONGs e de parte da sociedade que compartilham em prol da defesa dos direitos dos povos indígenas, atuando como intermediários nos conflitos entre esses povos e todas as ações danosas sofridas, ou anunciadas, por interesses estranhos que não compartilham da aceitação por parte desses povos, sejam eles de origem do próprio Estado, por meio de suas políticas e programas, ou da ação de empreendimentos que invadem os seus territórios para explorá-los.

No entanto, é importante destacar que as interações e relações entre as ações do Estado, as demandas dos povos indígenas e dentro do próprio movimento indigenista representam situações dialéticas, e não necessariamente conflituosas. Se por sua vez o Estado pode e age tanto na defesa quanto contra os interesses dos povos indígenas, em circunstâncias que atendam aos interesses econômicos (FONTELES, 2012), por outro, as reivindicações indígenas nem sempre reconhecem os poderes públicos simplesmente como tendo o poder para lhes proporcionar e garantir a reprodução dos seus modos de vida, os quais, organizados com grande autonomia, enfrentam o poder público. Ressalta-se, também, que o movimento indigenista, em virtude da autonomia para organização própria, apresenta diferentes perspectivas e aceitações dentre as diversas etnias e situações políticas do país. Cada povo tem seu conhecimento e organização social (REZENDE, 2004).

Considerando esses argumentos postos, muitas questões podem ser levantadas como plausíveis para tentar uma aproximação de respostas a muitas outras. Iniciemos então pelos muitos questionamentos, os quais ao final já sabemos que terão respostas soltas, e por que não dizer ultrapassadas, uma vez que o para frente é imprevisível, com certas convicções de mudanças.

Assim sendo, quais os motivos para se discutir sobre povos indígenas? Que direitos têm esses povos, e a partir de qual olhar? Que direitos Ihes são propostos? Quais suas demandas e lutas? Quais definições Ihes são atribuídas (ciência, Estado, empreendimentos) e em que circunstâncias evocá-las? É possível delimitar, e como, a "distância" em que esses povos podem "andar" sem comprometer seus modos de vida? E se é possível falar em modo de vida, o que podemos definir por isso? É possível falarmos em um reencantamento pelas populações tradicionais? E para não continuarmos em questões que levariam páginas, terminamos esse momento com uma das questões chave: Quem são os povos indígenas? considerando a lente de quem enxerga a partir de fora e daqueles que enxergam a partir de dentro.

Não se pretende aqui pontuar cada uma dessas questões, mas esperamos traçar argumentos que perpassem como um fio condutor carregando debates que acreditamos "jogar" luz, possibilidades, na articulação de densidades teórico-metodológicas e analíticas como possibilidades de respostas, embora não acabadas, mas como ponte para uma contínua discussão, que possam ser plausíveis, e 
por que não dizer aceitáveis, para aproximações explicativas, contribuindo para outros ou novos debates e, é claro, também questionáveis, quanto às inquietações levantadas acima. É evidente que não pretendemos encerrar nada aqui, muito pelo contrário, pensamos em avançar com muitas das questões que envolvem os povos indígenas, as quais têm atraído atenções em vários âmbitos da sociedade, não só no Brasil, mas no mundo.

Nessa empreitada, em que se exige um fundamento teórico-metodológico que dê coerência na análise acima proposta optamos por utilizar as abordagens culturais no âmbito político e científico da Geografia, identificando no debate da pós-modernidade, não se referindo a uma ruptura com a modernidade, os elementos que atendam de maneira mais elucidatória aos objetivos aqui pretendidos, os quais entrecruzam o debate da cultura no tocante às hibridizações culturais e um reencantamento do mundo para interpretar as coisas e os sujeitos, com relações humanistas, do imaterial.

$\mathrm{Na}$ abordagem cultural da Geografia, em sua demarcação humana, a discussão referente à cultura pode ser identificada inicialmente em Friedrich Ratzel (1844-1904), na Escola da Paisagem Alemã, com influência posterior dos estudos dessa escola nos trabalhos desenvolvidos por Carl Ortwn Sauer na Escola de Berkeley, nos Estados Unidos, e nos trabalhos de gênero de vida lablacheanos, nos quais haveria uma forte presença dos aspectos culturais (BROEK, 1967). Ratzel deu ênfase às características culturais ao criticar as interpretações geográficas arraigadas aos ambientes locais quando da explicação da ocorrência de determinado traço (língua, tradição), quando para ele o procedimento geográfico seria questionar a origem do traço, uma preocupação seguida por Sauer, tomando a origem e a dispersão como pedra fundamental de seu trabalho em Geografia Cultural.

Para Claval (1999), o "estado da arte" dos estudos culturais na Geografia, em que se descreve a cultura, inicialmente foi concebido como sinônimo dos aspectos materiais sendo extensões do humano, as próteses e as técnicas, identificados por meio das observações técnicas, dos ritmos e das atividades instituintes dos gêneros de vida e das marcas humanas nas instituições das paisagens culturais. Com isso, se buscava os modos de existência dos grupos humanos, configurando-os como objetos indiretos de interesse, com enfoque voltado para a investigação das marcas culturais dos grupos humanos expressas na paisagem, nas casas, nos campos, nos mercados.

Isso nos permite pontuar a existência de uma distinção, seguindo Nabozny (2014), entre uma Geografia Social, que estudaria os grupos sociais, e uma Geografia Cultural, que analisaria os traços culturais, o que Broek (1967) concebe como um ponto de vista sociocultural na perspectiva do entendimento de que a Geografia estuda a Terra como moradia do homem e investiga o homem como habitante da Terra, com análises, sociais e culturais, dos modos de existência dos grupos humanos. 
De acordo com Claval (1999), esse momento entra em declínio no período entre 1950 a 1970, por motivos da centralidade de análises na materialidade, objetiva, que se obscurece com a modernização e homogeneização das técnicas e urbanização das sociedades. Em crítica a essa concepção, e com proposta em outra abordagem cultural, Duncan (2002), na Geografia Saueriana, prescreve que a significação da cultura teria um valor supraorgânico, um caráter ontológico, qualificando-a como uma entidade acima dos homens e não o fruto da sua imaginação criativa. Nessa análise, não haveria possibilidades de explicação dos conflitos, contestações e mudanças, mas uma homogeneidade consensual que seria expressa na paisagem humanizada.

É a partir do posto acima que pretendemos mediar o nosso debate, tomando o estudo da cultura, o qual perpassa para além da materialidade, como uma chave para interpretar os desafios e oportunidades vivenciados pelos povos indígenas no Brasil nas questões políticas, sociais e culturais, com maiores delineamentos no que se refere à demarcação das terras desses povos. Buscamos aqui enfatizar como a cultura opera no âmbito da produção e reprodução da vida (SERPA, 2007) e o papel das interações de comunicações para que as transversalidades e singularidades cheguem aos lugares promovendo mudanças significativas na materialidade, e até mesmo na imaterialidade, possibilitando 0 acontecer simultâneo de experiências quando essas transversalidades se cruzam.

Para isso, trataremos dos intercâmbios entre as sociedades indígenas e as não indígenas nos encontros e processos culturais que denominamos de hibridação, os quais modificaram/modificam o modo de falar sobre identidade, cultura, diferença, desigualdade e multiculturalismo (CANCLINI, 2015), sobretudo, no final do século XX, facilitado pelos movimentos globalizadores (rádio, televisão e internet). Para Canclini (2015), a hibridação pode ser entendida como processos socioculturais nos quais estruturas ou práticas discretas, as quais não necessariamente podem ser consideradas fontes puras, que existiam de forma separada, se combinam para gerar novas estruturas, objetos, práticas, interações e, talvez, novos processos simbólicos, ocorrendo, às vezes, de modo não planejado.

Para a análise da questão indígena nesse processo de hibridações podemos identificar os casamentos mestiços, as relações indígenas por acesso à política, exterior a seus territórios, universidades, saúde, proteção, entre outras ações que demarcam muitas misturas interculturais. Nesse processo ocorrem negações e adaptações que dão origem a uma "nova" cultura, com integrações ou fusões como mistura de hábitos, crenças e formas de pensamentos, assim como contradições ao que não se deixa hibridar, em um processo que é contínuo entre as sociedades indígenas e as não indígenas. Em certo sentido, podemos compreender que 0 indígena busca aprender a cultura do não indígena numa tentativa de entender as sociedades ao redor, como estratégia para se defender e sobreviver em uma nova realidade. 
No tempo atual, as fronteiras éticas, das quais nos falam Poutignat e Streiff-Fenart (1998) e Barth (1969), que marcam o sistema social ao qual os atores acham que pertencem e para além das quais eles identificam outros atores implicados em um outro sistema social, não representam barreiras. Elas nunca são oclusivas, e sim mais ou menos fluidas, moventes e permeáveis, podendo manter-se, reforça-se, apagar-se ou desaparecer e, ainda, tornar-se mais flexíveis ou mais rígidas. 0 ponto importante é que a transposição das fronteiras pelos indivíduos não coloca em causa necessariamente sua pertinência social. Nesse sentido, um grupo étnico pode modificar e substituir sua cultura sem perder sua identidade, ele pode adotar os traços culturais de um outro e contudo continuar a ser percebido e perceber-se como distintivo.

Para Barth (2000), um grupo étnico pode ser definido como aquele que partilha de valores culturais fundamentais, realizados em unidade aberta sob formas culturais, o qual constrói uma esfera de comunicação e interação, em que seus membros se identificam e são identificados pelos outros como tal, constituindo assim uma categoria distinta de outras categorias da mesma ordem. Os grupos étnicos possuem padrões valorativos que os definem em quanto tal e a forma como cada grupo ou cada um irá se portar em contato com outros grupos, na interação interétnica, com o intuito de adquirir visibilidade e dialogar com o outro. No entanto, esses padrões não são fixos, podem mudar e adquirir novos significados em outro momento, conforme o contexto social.

Pode haver entradas e saídas na intercultura, em um movimento de trânsito, com encontros produtivos ou de conflitos, muito mais entradas do que saídas, em um processo que dificilmente não conduz o retorno ao anterior, com práticas incompatíveis ou contraditórias, uma vez que as marcas do encontro foram apreciadas, as quais podem encontrar terrenos para serem desenvolvidas quando consideradas como uma possível alternativa para uma dada situação. Referimos-nos, então, a uma hibridação como um processo ao qual é possível ter acesso e que se pode abandonar, em uma relação de desigualdades entre culturas.

Entendemos aqui que cultura é um termo dotado de diversas acepções, sendo um termo polissêmico com amplos debates nas ciências sociais, empregado no senso comum e inteligível no âmbito das ideias em discussão (CORRÊA, 2009). Para Hoefle (1998), a cultura pode ser entendida numa perspectiva abrangente ou restrita, abarcando inúmeros fenômenos (crença, hábitos, conhecimentos, linguagem, arte, etc.) ou limitada aos significados construídos a respeito das diferentes esferas da vida. A geografia saueriana está calcada na visão abrangente da cultura, enquanto na geografia cultural renovada a visão de cultura é restrita. Em Canclini (2015) a cultura é tida como um processo em constante transformação, adotando uma postura de mobilidade e ação, em que todas as culturas possuem formas próprias de organização e características que lhes são intrínsecas. 
Por nossa vez, assumimos o entendimento de que a cultura é uma propriedade humana ímpar, baseada em uma forma simbólica, de comunicação, vida social e a qualidade cumulativa de interação humana (MINTZ, 2009), se referindo a todos os produtos comportamentais, espirituais e materiais da vida social humana (TYLOR, 1920). Para Bader (2013, p. 133), o conceito de cultura inclui:

(a) cultura "material", tradições, modos de vida: alimentos, instrumentos, vestuário, casas, arte, rituais, cerimônias, festas; (b) aspectos específicos "simbólicos": linguagem, padrões étnicos cognitivos e normativos ("valores" e "normas partilhadas") e mundividências; (c) "redes/coesão" (incluindo a amizade, o casamento), associações e organizações étnicas, englobando meios de comunicação, organizações de interesses, partidos políticos (BADER, 2013, p. 133).

\section{O encontro, desencontro e reencontro de dois "mundos"}

Em um contexto de transformações e mudanças, de proximidades e inserções em um mundo de muitas interações e ao mesmo tempo de resistências e distanciamentos, em que as populações indígenas denunciam invasões de seus territórios, as quais colocam em risco o seu modo de vida, e apelam para o reconhecimento territorial como um direito básico assegurado pela constituição federal para a manutenção da sobrevivência e não perda de identidade cultural, é no qual podemos identificar o encontro, o desencontro e o reencontro entre os povos indígenas e os não indígenas, em que aqueles clamam pelo direito de "Existir", ainda que em meio às possibilidades entre circular entre as identidades e misturá-las, em que é difícil conservar as identidades culturais intactas, com adaptações que acontecem juntamente com as mudanças sociais, políticas e econômicas (HALL, 1999).

De acordo com Quermes e Carvalho (2013), o crescimento das cidades elevou o contingente populacional em regiões próximas das áreas indígenas, provocando uma aproximação forçada entre os índios e a população não indígena. No entanto, devemos postular que os índios não perdem sua condição étnica pelo fato de se dirigirem à cidade, falarem português ou usarem vestimentas dos demais integrantes da sociedade envolvente. Mas, por outro lado, é, também, salutar reconhecer que em muitos contextos os índios foram obrigados a se adaptar, buscando meios de sobrevivência alternativos, já que seus modos de vida não podem ser praticados de maneira plena na nova realidade. Essa nova realidade é a urbanização, o meio urbano, no qual, segundo dados do IBGE e FUNAI (2010), vivem 39\% dos indígenas, com maior destaque para as regiões Nordeste e Sudeste, sendo que nesta última a maioria da população indígena vive na zona urbana.

São novas relações, em que os indígenas circulam levando e trazendo costumes, estendidos pela televisão ou pelo rádio, os quais provocam novas formas de enxergar os estereótipos tanto a partir daquele que olha de dentro dos povos indígenas quanto dos olhares a partir de fora, fruto da imbricada relação das identidades individuais, coletivas e midiáticas. Os exemplos de tantos encontros, desencontros e reencontros ocorrem a partir de acordos em áreas como educação, saúde, segurança, 
política, informação, habitação, entre outros, e nos conflitos e embates em questões que não são aceitas pelas populações indígenas, as quais identificam ameaças à reprodução dos seus modos de vida em várias atividades executadas em seus territórios (abertura de rodovias, construção de hidrelétricas) e nas reaproximações na busca por solução de conflitos.

As lutas dos povos indígenas no contexto de encontros, desencontros e reencontros com as sociedades envolventes é persistente ao longo da história. Em decorrência disso, se formou e se organizou nas últimas décadas um quadro de direitos, os quais se fundamentam no Convênio sobre Povos Indígenas e Tribais (convênio 169), em 1989, da Organização Internacional do Trabalho - OIT, o qual reconhece pela primeira vez os direitos coletivos dos povos indígenas; na Declaração das Nações Unidas sobre os Direitos dos Povos Indígenas, em 2007, a qual propõe o direito desses povos à livre determinação; e na recente Declaração Americana sobre os Direitos dos Povos Indígenas, em 2016 (BRAGATO; BIGOLIN NETO, 2017). Para além desses grandes marcos, destacam-se também os acordos internacionais em prol das questões indígenas como a Cúpula da Terra (1992), a Conferência Mundial de Direitos Humanos (1993), a Conferência Internacional sobre População e Desenvolvimento (1994) e a Quarta Conferência Mundial da Mulher (1995).

Os povos indígenas têm sidos conceituados em vários âmbitos. Na doutrina interamericana, jurisprudência do Tribunal Interamericano de Direitos Humanos, sentença de 31 de agosto de 2001, série $C, n^{\circ} 66$, parágrafo 83 , diz o seguinte:

Os povos indígenas se definem como aqueles grupos sociais e humanos, identificados em termos culturais e que mantém uma continuidade histórica com seus antepassados, desde a época anterior a chegada a este continente dos primeiros europeus. Esta continuidade histórica é presente nas formas de organização, na cultura própria, na autoidentificação que estes povos fazem de si mesmos e na gestão de uma língua cujas origens são préhispânicos. (Tradução do autor).

Para a Organização das Nações Unidas (ONU), no documento E/CN.4/Sub.2/1986/7/Add.4, parágrafo 379, de 1987, os indígenas são conceituados da seguinte maneira:

Povos, comunidades e nações indígenas serão aqueles que, tendo uma continuidade histórica com sociedades pré-invasão e pré-coloniais que se desenvolveram nos seus territórios, se consideram distintos de outros setores das sociedades agora prevalecentes nesses territórios ou em parte deles. Atualmente, representam setores não dominantes da sociedade e estão determinados em preservar, desenvolver e transmitir às gerações futuras os seus territórios ancestrais e a sua identidade étnica, com base da sua existência continuada como povos, de acordo com os seus próprios padrões culturais, instituições sociais e sistemas jurídicos. (Tradução do autor).

Para o Banco Interamericano de Desenvolvimento (BID), segundo o documento Política operativa sobre pueblos indígenas, elaborado pelo departamento de Desenvolvimento Sustentável, Unidade de Povos Indígenas e Desenvolvimento Comunitários, Washington, 22 de fevereiro de 2006, parágrafo 1.1, os povos indígenas se referem: 
aos povos que cumprem os seguintes três critérios: (i) são descendentes dos povos que habitavam a região da América Latina e o Caribe na época da conquista o colonização; (ii) qualquer que seja sua situação jurídica ou localização atual, conservam, parcial ou totalmente, suas próprias instituições e práticas sociais, econômicas, políticas, linguística e culturais; e (iii) se autoidentificam como pertencentes a povos ou culturas indígenas ou précoloniais. (Tradução do autor).

Nosso objetivo, com as conceituações acima, não é debater sobre o conceito de povos indígenas, mas evidenciar que o conceito de povos indígenas, segundo variados âmbitos, se define pela historicidade, tendo raízes e especificidades culturais próprias decorrentes do seu processo de afirmação como povo, também se define pela sua contemporaneidade, a qual pressupõe 0 reconhecimento da sua óbvia existência atual e a garantia dos seus direitos individuais e coletivos, sendo um imperativo que cada Estado Ihes proporcione o direito à vida, à integridade física, a não violação dos direitos humanos, os quais conformam uma unidade indivisível, interdependente e interrelacionada, capaz de conjugar o catálogo de direitos civis e políticos ao catálogo de direitos econômicos, sociais e culturais (TRINDADE, 1991).

Em atendimento as essas questões o ordenamento jurídico brasileiro criou preceitos constitucionais pela necessidade de salvaguardar os direitos dos povos indígenas, com a garantia de tais direitos no nível hierárquico mais alto do Direito Interno, os quais estão reconhecidos na Constituição Federal do Brasil de 1988, em seus artigos 231 e 232, com a seguinte redação no artigo 231:

São reconhecidos aos índios sua organização social, costumes, línguas, crenças e tradições, e os direitos originários sobre as terras que tradicionalmente ocupam, competindo à União demarcá-las, proteger e fazer respeitar todos os seus bens.

É interessante ressaltar aqui um dos aspectos importantes no marco da constituição de 1998, e que iremos discutir com mais ênfase adiante, o que diz respeito aos direitos dos povos indígenas sobre as terras que tradicionalmente ocupam, reafirmando que a posse das mesmas é anterior à formação do próprio Estado, existindo, portanto, independentemente de qualquer reconhecimento oficial, ainda que isso não se configure na realidade atual como posta e vivenciada pelos povos indígenas, os quais lutam por terem seus direitos garantidos em seu cotidiano, em particular, pela demarcação das suas terras, o que tem gerado controvérsias pelas próprias representações do poder público e conflitos quanto às suas dimensões, o que para os povos indígenas perpassam para muito além de aspectos físicos e materiais.

Segundo Gallois et. al. (2018, p. 33),

[...] a Constituição Federal de 1988 tornou-se um marco histórico para os povos indígenas ao reconhecer a eles "sua organização social, costumes, línguas, crenças e tradições, e os direitos originários sobre as terras que tradicionalmente ocupam" (artigo 231), garantindo simultaneamente a cidadania plena e, portanto, a inserção nos direitos universais, e o direito 
à diferença, para o qual alguns direitos diferenciados, como os relativos ao atendimento em saúde e em educação, foram formulados.

\section{Os povos indígenas e suas terras no Brasil}

Os povos indígenas constituem atualmente mais de 370 milhões de indivíduos no mundo, representando cerca de $5 \%$ da população mundial e 10\% da população da América Latina (ONU, 2010). No Brasil existem cerca de 240 povos indígenas, 240 sociedades indígenas diferentes entre si, as quais falam em torno de 170 línguas diferentes, distribuídos em 622 terras indígenas reconhecidas pelo governo federal, correspondendo a $13,8 \%$ do território nacional; eles estão dispersos nos mais diversos pontos do país, com grande concentração das terras na Amazônia, 98\% (IBGE, 2010; FUNAI, 2018) (figura 01). O Brasil possui uma imensa diversidade étnica e linguística, estando entre os maiores do mundo; as línguas faladas pelos membros das sociedades indígenas pertencem a mais de 30 famílias linguísticas diferentes (CARVALHO, 2013).

Segundo a FUNAI (2010), vivem, atualmente, cerca de 850.000 indígenas no Brasil, representando menos de $0,5 \%$ da população total do país. Eles constituem efetivamente, em termos demográficos, uma minora, mas esse ínfimo percentual populacional esconde uma diversidade cultural e linguística frequentemente ignorada e desconhecida (GALLOIS et. al., 2016). Segundo Wiig (2013), a população indígena no Brasil está crescendo, assim como o número de etnias, embora alguns povos estejam ameaçados de extinção. Há também 82 referências de grupos indígenas ainda não contatados, "os isolados" dos quais 32 foram confirmados, e a existência de grupos que estão requerendo o reconhecimento de sua condição de "indígenas", os quais, em geral, foram obrigados durante períodos repressivos a mascarar sua identidade étnica, a fim de preservar a própria vida (CARVALHO, 2013). 
Figura 01: Localização das terras indígenas por situação fundiária.

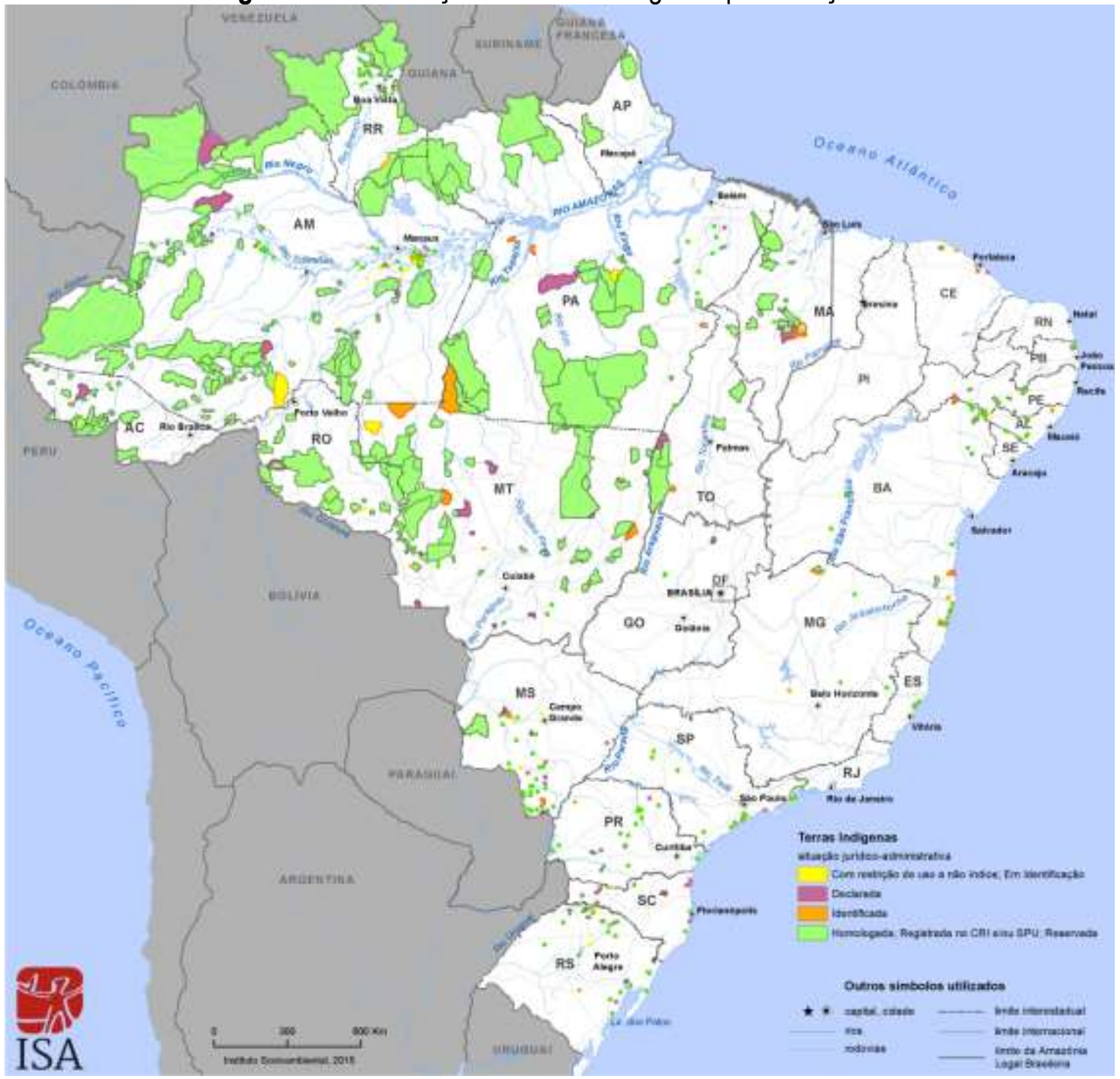

Fonte: Instituto Socioambiental - ISA (2015).

A diversidade cultural dos povos indígenas demonstra a multiplicidade de povos e das suas relações com o meio ambiente, com o meio mítico religioso e a variação de tipos de organizações sociais, políticas e econômicas, de produção de material e de hábitos cotidianos de vida, o que faz com que os modos de vida dos povos indígenas variem de povo para povo conforme o tipo de relações que é estabelecido com o meio natural e o sobrenatural. A organização social, cultural e econômica de um povo indígena encontra-se relacionada a uma concepção de mundo e de vida, por uma determinada cosmologia organizada e expressa por meio dos mitos e dos ritos, os quais orientam a vida social, os casamentos, o uso de extratos vegetais, minerais ou animais na cura de doenças, além de muitos hábitos cotidianos (LUCIANO, 2006).

Tradicionalmente, os povos indígenas tinham apenas lideranças denominadas tradicionais, ou seja, os caciques ou tuxauas, os quais tinham a função de organizar, articular e representar o povo 
diante de outros povos. No entanto, o surgimento de organizações indígenas, como necessidade das novas relações com as sociedades não indígenas, regional, nacional ou internacional, como mediadoras, veio modificar a configuração dos espaços de poder presentes nas comunidades e povos indígenas, quando novas pessoas passaram a ter funções importantes na vida coletiva, na figura dos dirigentes de organizações indígenas, dos professores, dos agentes indígenas de saúde e de outros profissionais indígenas. Ainda que diante de novas realidades, as culturas indígenas em grande medida têm conservado sua singularidade em face das sociedades não indígenas, no constante encontro de culturas, em que as fronteiras não nos permitem mais pensar no isolamento restrito desses povos, ressalvadas possíveis exceções.

O grande desafio dos povos indígenas é como garantir definitivamente os seus direitos de posse e exclusividade às suas terras tradicionais em determinadas condições sociojurídicas na sociedade brasileira contemporânea, sem necessidade de abrir mão do que the é próprio, as culturas, as tradições, os conhecimentos e os valores. Nesse sentido, a demarcação das terras onde vivem e a proteção ao meio ambiente são indispensáveis para garantir sua sobrevivência física e cultural, sendo a terra um fator fundamental de resistência dos povos indígenas, o que unifica, articula e mobiliza todos, as aldeias, os povos e as organizações indígenas em torno de uma bandeira de luta comum que é a defesa de seus territórios. É interessante perceber como na luta pelo direito à terra as lideranças, locais e tradicionais, mesmo sendo muitas vezes analfabetas, adquirem prestígio tanto no nível interno da comunidade quanto na relação com a sociedade nacional e internacional (LUCIANO, 2006).

Segundo a FUNAI (2018), as terras indígenas correspondem a 118.205.950,0108 de hectares, os quais se encontram distribuídos em várias categorias no procedimento demarcatório das terras indígenas (terras delimitadas, declaradas, homologadas, regularizadas, reservas indígenas e terras interditadas). Do total das terras indígenas, 89,15\% (105.376.348,6835 ha), a maior parte, está com situação regularizada, ou seja, são terras que já foram homologadas por decreto e estão registradas em cartório em nome da União e na Secretaria do Patrimônio da União. Também, é significativo o número de terras, mas de extensão não conhecida, que se encontra em fase de estudos (114), com a realização de estudos antropológicos, históricos, fundiários, cartográficos e ambientais, os quais fundamentam a identificação e a delimitação da terra indígena (Tabela 01). 
Tabela 01: Situação fundiária das terras indígenas no Brasil, ano de 2013.

\begin{tabular}{|c|c|c|c|}
\hline & $N^{0}$ de terras indígenas & Porcentagem (\%) & Superfície (ha) \\
\hline Em estudo & 114 & - & $4.403 .633,9658$ \\
\hline Delimitada & 44 & 3,73 & $5.420 .026,3090$ \\
\hline Declarada & 72 & 4,59 & $1.846 .954,4051$ \\
\hline Homologada & 15 & 1,56 & $105.376 .348,6835$ \\
\hline Regularizada & 435 & 89,15 & $78.246,6464$ \\
\hline Reserva indígena & 50 & 0,06 & $1.080 .740,0000$ \\
\hline Interditadas & 6 & 0,91 & $118.205 .950,0108$ \\
\hline Total & 736 & 100 & \\
\hline
\end{tabular}

Fonte: FUNAI (2018).

De maneira mais geral, a intensa pressão econômica tem atingido com bastante força as terras indígenas nos últimos anos com as frentes de expansão (agrícola, pastoril e mineral), as quais avançam sobre os mais longínquos recantos de florestas e terras nativas, provocando invasões, degradações, reduções, e com novos desafios para seus habitantes, onde, infelizmente, os tentáculos do capitalismo alcançam os povos indígenas, corrompendo algumas lideranças, as quais, em consentimento com fazendeiros e pecuaristas em troca de minguados recursos de ordem material acabam cedendo às demandas destes, em particular no arrendamento de suas terras, o que é ilegal por lei, embora que esta, apesar da clareza em assegurar os direitos desses povos na constituição federal, seja questionada pela interferência do poder judiciário nos processos de reconhecimento e regularização das terras indígenas, o qual apresenta tendências em prol das questões políticas e econômicas, em exemplos que se estendem por todo o Brasil, agindo contra os direitos dos povos indígenas.

Se por um lado encontram-se aqueles que se posicionam terminantemente contra a demarcação das terras indígenas, por julgarem que isso representa um atentado ao direito de propriedade, além de atrapalhar a implantação dos ideais liberais e desenvolvimentistas, por outro, estão os povos indígenas e seus apoiadores, as igrejas, as ONGs e aqueles que se identificam com um "reencantamento" pelas questões indígenas, os quais exigem a efetivação dos direitos territoriais indígenas que thes foram reconhecidos pela Carta Magna brasileira, na qual se reconhece a "originalidade" do direito dos índios, o direito "congênito", anterior a todos os outros reconhecidos pelo ordenamento jurídico brasileiro, um reconhecimento do fato histórico de que os índios foram os primeiros ocupantes do Brasil, com direito às terras de ocupação tradicional, e ampliou a compreensão 
de "terra indígena" (CAVALCANTE, 2016). Sobre isso, a constituição federal de 1988 declara 0 seguinte no artigo 231 , parágrafos $1^{\circ}, 2^{\circ}, 3^{\circ}$ e $4^{\circ}$ :

\begin{abstract}
Art. 231. São reconhecidos aos índios sua organização social, costumes, línguas, crenças e tradições, e os direitos originários sobre as terras que tradicionalmente ocupam, competindo à União demarcá-las, proteger e fazer respeitar todos os seus bens.

$\S 1^{\circ}$ - São terras tradicionalmente ocupadas pelos índios as por eles habitadas em caráter permanente, as utilizadas para suas atividades produtivas, as imprescindíveis à preservação dos recursos ambientais necessários a seu bem-estar e as necessárias a sua reprodução física e cultural, segundo seus usos, costumes e tradições.

$\S 2^{\circ}$ - As terras tradicionalmente ocupadas pelos índios destinam-se a sua posse permanente, cabendo-Ihes o usufruto exclusivo das riquezas do solo, dos rios e dos lagos nelas existentes.

$\S 3^{\circ}$ - 0 aproveitamento dos recursos hídricos, incluídos os potenciais energéticos, a pesquisa e a lavra das riquezas minerais em terras indígenas só podem ser efetivados com autorização do Congresso Nacional, ouvidas as comunidades afetadas, ficando-lhes assegurada participação nos resultados da lavra, na forma da lei.

$\S 4^{\circ}$ - As terras de que trata este artigo são inalienáveis e indisponiveis, e os direitos sobre elas, imprescritiveis.
\end{abstract}

A referência constitucional aos direitos pelas terras de ocupação tradicional traz-nos a compreensão de que a demarcação dos territórios indígenas não se pode limitar apenas aos espaços necessários para a habitação e reprodução econômica desses povos, mas também há de considerar a relevância para a sua cultura, religião e organização social. Identificados esses elementos caberia apenas ao Estado reconhecê-los, por simplesmente precisar a real extensão da posse para assegurar a plena eficácia do dispositivo constitucional, em ato meramente declaratório. No entanto, isso tem se configurado em um cenário de longas disputas, em que o Estado se apresenta resistente em não atender, ou melhor, não entender, mergulhado nos interesses políticos e econômicos, os reclamos pelas extensões das áreas requeridas pelos próprios indígenas para demarcação, os quais argumentam em referência à sua cultura uma projeção espacial para áreas muito além daquelas hoje reconhecidas ou em processo de reconhecimento pelo Estado.

Segundo Luciano (2006), os desencontros entre o Estado e os povos indígenas pela real extensão das terras têm suas explicações e origens para antes da constituição de 1988 quando 0 direito dos povos indígenas sobre suas terras era muito pouco claro, o que permitia inúmeras interpretações, deixando nas mãos dos administradores públicos e dos dirigentes políticos concederem ou não os direitos segundo condições e critérios geralmente muito subjetivos e aleatórios, o que levou a demarcação de terras muito reduzidas e insuficientes para garantir a sobrevivência mínima das comunidades indígenas, em afinidade com teses políticas, econômicas e acadêmicas que sustentavam que os índios constituíam populações minoritárias sobreviventes, decadentes e transitórias, cujo único futuro era a integração total à "comunhão nacional".

No entanto, todas as previsões e teorias políticas e científicas não se consolidaram, fazendo com que a partir da década de 1970 os povos indígenas no Brasil iniciassem um período de 
recuperação demográfica e de autoestima identitária, provocando uma crescente pressão por retomadas e ampliações de suas terras em todos os cantos do país, tendo um forte apoio da sociedade brasileira, notadamente da Igreja, da sociedade civil organizada e da academia, os quais lutam por garantir os direitos dos povos indígenas consolidados na constituição federal de 1988.

Não podemos entender a posse indígena da terra limitada à mera ocupação ou exploração econômica, não apenas para a sobrevivência física do grupo, mas também para a sua sobrevivência cultural (DA SILVA, 2003). Nesse sentido, os povos indígenas estabelecem um vínculo estreito e profundo com a terra, não contido apenas no aproveitamento do solo agrário, mas alcançando 0 sentido de territorialidade, em que o território é o habitat onde viveram e vivem os antepassados e está ligado às suas manifestações culturais, às tradições, às relações familiares e sociais.

A territorialidade indígena é exigida como um espaço socionatural necessário para se viver individual e coletivamente, o que não é compreensível pelas autoridades e sociedades não indígenas que insistem em demarcações de terras com limites de áreas considerando uma mentalidade orientada segundo as necessidades de espaços para os que vivem em cidades, individualizados, onde não se exigem espaços territoriais amplos e coletivos, ou no campo, onde o modo de vida é guiado por outras formas de relações com a terra. Para os indígenas a terra é um elemento central da identidade cultural e de seu desenvolvimento social e físico (FONTELES, 2012), não se resumindo a um lugar de habitação.

Os povos indígenas precisam de espaços suficientes de terras para caçar, pescar e desenvolver suas tradições culturais e seus rituais sagrados, os quais só podem ser praticados em ambientes adequados; a sua cultura está totalmente ligada aos rios, cachoeiras, florestas e matas. A falta de terra, ou a sua insuficiência, acarreta não apenas dificuldades de sobrevivência física das comunidades indígenas, mas ameaça a própria continuidade étnica, na medida em que impede a realização de práticas tradicionais como os rituais, as cerimônias, as festas e outras tradições fundamentais para a reprodução da cultura ancestral do povo. Para os indígenas, a própria continuidade e reprodução cultural dependem do direito à terra. A relação deles com suas terras, territórios e recursos naturais constitui um elemento essencial do direito à livre determinação, é fonte de identidade cultural, conhecimentos e espiritualidade e se relaciona estritamente com sua sobrevivência (CEPA, 2015).

Segundo a Comissão Interamericana de Direitos Humanos - CIDH (2009), a relação dos povos indígenas com a terra não é meramente uma questão de posse e produção, mas se configura como um elemento material e espiritual do qual devem gozar plenamente, para preservar seu legado cultural e transmiti-lo às gerações futuras. As tradições e costumes indígenas estão intimamente atrelados à 
terra, sendo então a posse da terra essencial a sua sobrevivência. 0 vínculo espiritual e de ancestralidade não permite que os indígenas ocupem qualquer pedaço de terra, pois eles pertencem ao local onde suas famílias nasceram e viveram (RIBEIRO, 1962).

Assim, 0 acesso às dimensões de terras reclamadas tem ênfase em garantir a esses povos a possibilidade de conservar sua cultura e seus costumes, de criar suas próprias instituições e de participar efetivamente nas decisões sobre a exploração de recursos naturais contidos em suas terras. A relação dos indígenas com seus territórios possui dimensões de incidência social, cultural, espiritual, econômica e política. É por conta disso que os indígenas lançam suas lutas e resistências, exigindo a demarcação de suas terras, em que as definições ocorram de acordo com a sua própria cultura, o que Ihes é assegurado na lei.

A luta pela terra é uma demanda constante, intensificada atualmente com o fenômeno conhecido como "etnogenêse", o qual ocorre quando um povo étnico consegue reassumir e reafirmar sua identidade étnica por razões históricas, a qual havia sido reprimida em determinadas circunstâncias, também históricas, recuperando aspectos relevantes de sua cultura tradicional e demandando seus direitos e recursos, demandas por novas demarcações de terras (BARTOLOMÉ, 2006; VILLARES, 2013). Ainda que exista a possibilidade de reparação aos povos indígenas pelas perdas e invasões de seus territórios com uma indenização pecuniária ou de qualquer outra reparação "adequada" (ONU, 2007), estes apenas exigem as suas terras, o direito de "Existir" conforme suas culturas, mesmo não renegando suas interações com as sociedades não indígenas.

\section{Considerações finais}

É fato que a partir do contato com as sociedades não indígenas as culturas dos povos indígenas sofreram modificações, uma vez que dentro das etnias se operam processos de mudança sociocultural, que sobremaneira podem ser inseridas nas matrizes cosmológicas e míticas em torno das quais gira toda a dinâmica da vida tradicional, em um movimento que aqui identificamos como hibridação.

Esse não é o maior desafio para a continuidade e conservação da cultura dos povos indígenas em suas singularidades, mas a luta pela demarcação de suas terras, em que sejam consideradas na extensão dessas a espacialização das suas atividades política, econômica, social e, especialmente, cultural, com demandas que estão muito além dos espaços considerados pelas sociedades não indígenas como necessários para a reprodução material e imaterial desses povos.

As garantias asseguradas pela constituição federal de 1988 às terras indígenas são fundamentais à preservação cultural dos povos indígenas, mas a morosidade administrativa e a ampla 
judicialização dos casos de demarcação de terras indígenas trazem cada vez mais à tona as diversas subjetividades presentes nos discursos jurídicos, carregadas por interesses políticos e econômicos, em detrimento dos interesses das populações indígenas.

Enfim, ainda que contestados e controversos muitos dos números oficiais sobre as terras indígenas no Brasil, é fato, considerando os diversos interesses por tais terras, a existência de muito mais terras sendo reivindicadas por povos e comunidades indígenas. Ainda, a demarcação por si só não representa segurança e garantias aos indígenas, é preciso controlar adequadamente as invasões. O êxito pelo atendimento das reivindicações dos povos indígenas no Brasil depende necessariamente do grau de comprometimento nessa direção por parte de todos aqueles que atuam nessa questão.

\section{Referências}

BADER, V. Etnicidade e classe: um exercício para um mapeamento teórico. In: SILVA, M. C.; SOBRAL, J. M. (Org.). Etnicidade, nacionalismo e racismo: migrações, minorias étnicas e contextos escolares. Porto: Edições Afrontamento, 2013.

BARTOLOMÉ. M. A. As etnogêneses: velhos atores e novos papéis no cenário cultural e político. Revista Mana. Vol. 12, no 1, p. 39-68. Rio de Janeiro, 2006.

Banco Interamericano de Desenvolvimento - BID. Política operativa sobre pueblos indígenas.

Departamento de Desenvolvimento Sustentável. Unidade de Povos Indígenas e Desenvolvimento Comunitário. Washington, 2006.

BARTH, F. Ethnic Groups and Boundaries - The Social Organization of Cultural Difference. BergenOslo/Boston: Universitets Forlaget/Little Brown, 1969.

O guru, o iniciador: e outras variações antropológicas. Contra Capa. Tradução de Jhon Cunha Comerford. Rio de Janeiro, 2000.

BRAGATO, F. F.; BIGOLIN NETO, P. Conflitos territoriais indígenas no Brasil: entre risco e prevenção. Revista Direito e Práxis. Vol. 8, no 1, p. 156-195. Rio de Janeiro-RJ, 2017.

BRASIL. Constituição da República Federativa do Brasil. Senado Federal: Centro Gráfico. Brasília-DF, 1988.

BROEK, J. O. M. Iniciação ao estudo da Geografia. Rio de Janeiro: Jorge Zahar, 1967. 155p.

CANCLINI, N. G. Culturas Híbridas: Estratégias para Entrar e Sair da Modernidade. São Paulo: Edusp

- Editora da Universidade de São Paulo, 2015.

CARVALHO, M. L. B. Das terras dos índios a índios sem terras. O Estado e os Guarani Oco'y: violência, silêncio e luta. Tese (Doutorado em Geografia). FFLCH/USP. São Paulo-SP, 2013.

CAVALCANTE, T. L. V. "Terra Indígena": aspectos históricos da construção e aplicação de um conceito jurídico. História. Vol. 35, e75. São Paulo-SP, 2016.

Comissão Econômica para a América Latina e o Caribe - CEPAL. Os povos indígenas na América Latina: avanços na última década e desafios pendentes para a garantia dos seus direitos. Nações Unidas. Chile, 2015 (síntese).

Comissão Interamericana de Direitos Humanos - CIDH. Derechos de los Pueblos Indígenas y Tribales sobre sus tierras ancestrales y recursos naturales. Normas y jurisprudencia del Sistema Interamericano de Derechos Humanos. OEA/Ser.L/V/II. Doc. 56/09. Dezembro de 2015.

COBO, J. R. M. Study of the Problem of Discrimination Against Indigenous Populations. Organização da Nações Unidas, Doc. E/CN.4/Sub.2/1986/7/Add.4, §379, 1987. 
CORRÊA, L. R. Sobre a Geografia cultura. Instituto Histórico e Geográfico do Rio Grande do Sul, 2009. Disponível em (http://ihgrgs.org.br/artigos/contibuicoes/Roberto\%20Lobato\%20Corr\%C3\%AAa\%20$\% 20$ Sobre\%20a\%20Geografia\%20Cultural.pdf). Data de acesso: junho de 2018.

CLAVAL, P. Geografia Cultural: o Estado da Arte. In: CORREAA, R. L.; ROSENDAHL, Z. (Orgs.). Manifestações da cultura no espaço. Rio de Janeiro: UERJ, 1999. p. 59-97.

DA SILVA, J. A. Curso de Direito Constitucional Positivo. São Paulo: Malheiros Editores, 2003. p. 828829.

DUNCAN, J. S. O Supraorgânico na Geografia Cultural americana. Espaço e Cultura. № 13, p. 7-33, jan./jun. Rio de Janeiro-RJ, 2002.

FONTELES, G. M. Povos indígenas e globalização - Redes Transnacionais de Apoio a Causas Indígenas e a Usina Hidrelétrica de Belo Monte: Um estudo exploratório. Dissertação (Mestrado em Relações Internacionais). Universidade de Brasília/Instituto de Relações Internacionais. Brasília-DF, 2012.

Fundação Nacional do índio. Índios no Brasil: quem são? 2010. Disponível em (http://www.funai.gov.br/index.php/indios-no-brasil/quem-sao?start=3\#). Data de acesso: junho de 2018.

Modalidades de terras indígenas. Disponível em (http://www.funai.gov.br/index.php/indios-nobrasil/terras-indigenas). Data de acesso: setembro de 2018.

GALLOIS, D. T.; KLEIN, T.; DAL'BO, T. L. Povos Indígenas, Políticas Multiculturais e Políticas da Diferença. Revista de Cultura e Extensão USP. № 15, p.31-48, mai. São Paulo-SP, 2016. Disponível em (http://dx.doi.org/10.11606/issn.2316-9060.v15i0p31-48). Data de acesso: setembro de 2018. HALL, S. A identidade cultural na pós-modernidade. Tradução: SILVA, T. T.; LOURO, G. L. $3^{a}$ edição. Rio de Janeiro: DP\&A, 1999.

HOEFLE, S. W. Cultura na História do Pensamento Científico. Revista da PósGraduação em Geografia - Universidade Federal do Rio de Janeiro. № 2, p. 6-29. Rio de Janeiro-RJ, 1998.

Instituto Brasileiro de Geografia e Estatística - IBGE. Estatística das populações indígenas, 2010. Disponível em

(http://www.ibge.gov.br/home/estatistica/populacao/tendencia_demografica/indigenas/indigenas.pdf). Data de acesso: junho de 2018.

Instituto Socioambiental - ISA. Localização e extensão das TIs. Povos indígenas no Brasil, 2015. Disponível em (https://img.socioambiental.org/d/922082-1/mapa_TI_brasil_2015_A4_2.jpg). Data de acesso: setembro de 2018.

LUCIANO, G. S. O Índio Brasileiro: o que você precisa saber sobre os povos indígenas no Brasil de hoje. Ministério da Educação, Secretaria de Educação Continuada, Alfabetização e Diversidade.

Brasília: LACED/Museu Nacional, 2006.

MINTZ, S. W. Cultura: uma visão antropológica, 2009. Disponível em (http://www.scielo.br/pdf/tem/v14n28/a10v1428.pdf). Data de acesso: junho de 2018.

NABOZNY, A. abordagens culturais na geografia brasileira: uma compreensão. Tese (Doutorado em Geografia). Universidade Federal do Rio Grande do Sul. Porto Alegre-RS, 2014.

Organização das Nações Unidas - ONU. A Declaração das Nações Unidas sobre os Direitos dos Povos Indígenas. Assembleia Geral das Nações Unidas, 2007.

State of the World's Indigenous Peoples. Secretariado do Fórum Permanente sobre Questões Indígenas, Nova York, 2010.

POUTIGNAT, P.; STREIFF-FENART, J. Teorias da etnicidade. Seguido de grupos étnicos e suas fronteiras de Fredrik Barth. Tradução de Elcio Fernandes. Fundação Editora da Unesp. São Paulo-SP, 1998. (biblioteca básica).

QUERMES, P. A. A.; CARVALHO, J. A. Os impactos dos benefícios assistenciais para os povos indígenas: estudo de caso em Aldeias Guaranis. Serv. Soc. Soc. No 116, p. 769-791, out./dez. São Paulo-SP, A2013. 
REZENDE, G. C. A relação entre indígenas e não-indígenas em escolas urbanas: um estudo de caso na cidade de Campinápolis-MT. Dissertação (Mestrado em Educação). UFMT/IE. Cuiabá-MT, 2004. RIBEIRO, D. A política indigenista brasileira. $1^{a}$ edição. Rio de Janeiro: Ministério da Agricultura, 1962. SAUER, C. O. Geografia Cultural. Espaço e Cultura. No 03, p. 1-7, jan. Rio de Janeiro, 1997. SERPA, A. culturas transversais: um novo referencial teórico-metodológico para a Geografia Humanista e Cultural? In: KOSEL, S.; SILVA, J. C.; GIL FILHO, S. F. (Orgs.). Da percepção e cognição à representação: reconstruções teóricas da Geografia Cultural e Humanista. Curitiba: Terceira Margem. NEER, 2007. p. 36-56.

TRINDADE, A. A. C. A proteção internacional dos direitos humanos: fundamentos jurídicos e instrumentos básicos. São Paulo: Saraiva, 1991.

TYLOR, E. B. Primitive culture: researches into the development of mythology, philosophy, religion language, art, and custom. Volume 1. London: Jhon Murray, Albemarle Street, 1920.

VILLARES, L. F. Terras Indígenas. In: VILLARES, L. F. Direito e Povos Indígenas. Curitiba: Editora Juruá, 2013. p. 95-139.

WIIG, A. M. Povos indígenas no Brasil: 1980/2013. Embaixada da Noruega/ISA. Brasília, 2013.

(Recebido em 20-06-2018; Aceito em: 28-09-2018) 